\title{
Genetic Analysis of Citrobacter sp.86 Reveals Involvement of Corrinoids in Chlordecone and Lindane Biotransformations
}

\section{OPEN ACCESS \\ Edited by: \\ Tian Zhang, \\ Wuhan University of Technology, \\ China \\ Reviewed by: \\ Shaohua Chen, \\ South China Agricultural University, \\ China \\ Sarra Gaspard, \\ Université des Antilles et de la \\ Guyane, France \\ *Correspondence: \\ Nuria Fonknechten \\ nuria.fonknechten@cea.fr \\ Denis Le Paslier \\ denis@genoscope.cns.fr}

tThese authors share first authorship

Specialty section: This article was submitted to

Microbiotechnology,

a section of the journal

Frontiers in Microbiology

Received: 03 August 2020

Accepted: 13 October 2020

Published: 09 November 2020

Citation:

Barbance A, Della-Negra O,

Chaussonnerie S, Delmas V,

Muselet D, Ugarte E, Saaidi $P$ - L,

Weissenbach J, Fischer $C$,

Le Paslier D and

Fonknechten N (2020) Genetic Analysis of Citrobacter sp.86 Reveals

Involvement of Corrinoids in

Chlordecone and Lindane Biotransformations.

Front. Microbiol. 11:590061.

doi: 10.3389/fmicb.2020.590061

\author{
Agnès Barbance ${ }^{1 \dagger}$, Oriane Della-Negra ${ }^{1 \dagger}$, Sébastien Chaussonnerie ${ }^{1}$, Valérie Delmas ${ }^{1}$, \\ Delphine Muselet ${ }^{1}$, Edgardo Ugarte', Pierre-Loïc Saaidi', Jean Weissenbach', \\ Cécile Fischer ${ }^{1}$, Denis Le Paslier ${ }^{1 *}$ and Nuria Fonknechten ${ }^{1,2 *}$
}

\begin{abstract}
'Génomique Métabolique, Genoscope, Institut François Jacob, CEA, CNRS, Univ Evry, Université Paris-Saclay, Evry, France, ${ }^{2}$ Laboratoire de Cancérologie Expérimentale, IRCM, Institut François Jacob, CEA, Université Paris-Saclay, Fontenay aux Roses, France
\end{abstract}

Chlordecone (Kepone $\left.{ }^{\circledR}\right)$ and $\gamma$-hexachlorocyclohexane $(\gamma$-HCH or lindane) have been used for decades in the French West Indies (FWI) resulting in long-term soil and water pollution. In a previous work, we have identified a new Citrobacter species (sp.86) that is able to transform chlordecone into numerous products under anaerobic conditions. No homologs to known reductive dehalogenases or other candidate genes were found in the genome sequence of Citrobacter sp.86. However, a complete anaerobic pathway for cobalamin biosynthesis was identified. In this study, we investigated whether cobalamin or intermediates of cobalamin biosynthesis was required for chlordecone microbiological transformation. For this purpose, we constructed a set of four Citrobacter sp.86 mutant strains defective in several genes belonging to the anaerobic cobalamin biosynthesis pathway. We monitored chlordecone and its transformation products (TPS) during longterm incubation in liquid cultures under anaerobic conditions. Chlordecone TPs were detected in the case of cobalamin-producing Citrobacter sp.86 wild-type strain but also in the case of mutants able to produce corrinoids devoid of lower ligand. In contrast, mutants unable to insert the cobalt atom in precorrin-2 did not induce any transformation of chlordecone. In addition, it was found that lindane, previously shown to be anaerobically transformed by Citrobacter freundii without evidence of a mechanism, was also degraded in the presence of the wild-type strain of Citrobacter sp.86. The lindane degradation abilities of the various Citrobacter sp.86 mutant strains paralleled chlordecone transformation. The present study shows the involvement of cobalt-containing corrinoids in the microbial degradation of chlorinated compounds with different chemical structures. Their increased production in contaminated environments could accelerate the decontamination processes.

Keywords: chlordecone, lindane, dechlorination, corrinoid, cobalamin, Citrobacter, gene deletion, degradation 


\section{INTRODUCTION}

Chlordecone is a toxic organochlorine persistent organic pollutant (POP) included in the Stockholm Convention in 2009 (Jennings and $\mathrm{Li}, 2015)$. It has been manufactured for several years in the United States (Epstein, 1978) until it was banned in 1975. Its production at the Hopewell plant (Virginia) led to acute exposure of workers and a massive pollution of the James River and its surroundings, which extended more than 100 miles toward the Chesapeake Bay (Dawson et al., 1979; Huggett and Bender, 1980). Since then, the contamination has been slowly declining, due to chlordecone burying over the time into riverbed sediments (Trotman and Nichols, 1978; Nichols and Cutshall, 1981; Nichols, 1990; Unger and Vadas, 2017). In banana plantations of the French West Indies (FWI, Guadeloupe and Martinique Islands), chlordecone usage for its insecticide properties against the banana black weevils lasted from 1972 until 1993 (Vilardebo et al., 1974; Le Déaut and Procaccia, 2009; Lesueur-Jannoyer et al., 2016), resulting in long-term pollution of environmental compartments and the local food chain (Lesueur-Jannoyer et al., 2016). Acute and chronic exposure to chlordecone was the cause of human health harm such as increased risk of prostate cancer, motor and cognitive development disorders in young children, premature births (Epstein, 1978; Multigner et al., 2018; Maudouit and Rochoy, 2019), and subsequent socio-economic issues for the FWI and James River areas (Lesueur-Jannoyer et al., 2016; Unger and Vadas, 2017).

Due to its specific chemical structure (a bis-homocubane cage) and its perchlorinated nature, chlordecone was considered as non-degradable in the environment for a long time (Epstein, 1978; Cabidoche et al., 2009), despite some laboratory-based evidences of transformation (Figure 1). Two studies suggested possible aerobic degradation of chlordecone (Orndorff and Colwell, 1980; George and Claxton, 1988). And later on, the conversion of chlordecone into unknown polar and nonpolar transformation products (TPs) in the presence of the anaerobic Archaeon Methanosarcina thermophila was reported (Jablonski et al., 1996). In 2011, the bacterium Pseudonocardia sp. KSF27 isolated from endosulfan-contaminated soils was also reported as transforming chlordecone in aerobiosis (Sakakibara et al., 2011). A very low level of chlordecone mineralization was also observed in a microcosm incubated during several months in aerobic conditions (Fernández-Bayo et al., 2013). However, no TP was described to confirm the apparent degradation in these two studies. More recently, we showed, that under anaerobic laboratory conditions, bacterial consortia and isolated bacteria (Citrobacter sp.86 and Desulfovibrio sp.86) could transform

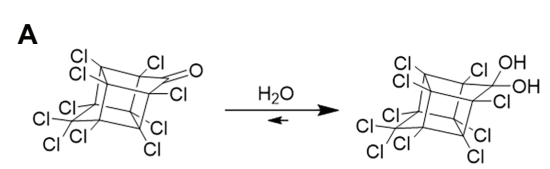

B

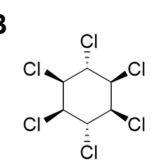

FIGURE 1 | (A) Chemical structure of chlordecone mostly present under its hydrated form Wilson and Zehr (1978). (B) Chemical structure of $\gamma$-hexachlorocyclohexane (lindane). chlordecone into numerous TPs of different types (Figure S1; Chaussonnerie et al., 2016; Della-Negra et al., 2020). In addition, we detected the same TPs in environmental samples from Martinique Island, suggesting that a similar natural degradation occurs in Martinique soils (Chevallier et al., 2019; Della-Negra et al., 2020). This phenomenon was independently confirmed by others with the detection of chlordecone TPs in Guadeloupe soils (Lomheim et al., 2020). However, to date, the mechanisms of chlordecone degradation remain unknown and do not seem to be mediated by organohalide-respiring bacteria.

Citrobacter sp.86, related to Citrobacter amalonaticus, has been isolated from a chlordecone-degrading bacterial consortium and its genome was sequenced (Chaussonnerie et al., 2016). This facultative anaerobic bacterium was demonstrated to fully transform chlordecone anaerobically. The chlordecone TPs produced by Citrobacter sp.86 were classified into three families: A (hydrochlordecones) resulting from dechlorination, B (polychloroindenes) arising from the opening of the bis-homocubane cage, dechlorination, and the loss of one carbon atom and two oxygen atoms, and $\mathrm{C}$ (polychloroindenecarboxylic acids) obtained from chlordecone ring-opening dechlorination (Chevallier et al., 2019; Figure S1). In the previously described microbiological conditions, TP B1 (2,4,5,6,7-pentachloroindene) was found predominant according to Gas Chromatography coupled to Mass Spectrometry (GC-MS) analysis. Similar TPs, belonging to families A and $\mathrm{B}$, were previously obtained by chemical degradation of chlordecone in the presence of vitamin $\mathrm{B}_{12}$ (Schrauzer and Katz, 1978; Ranguin et al., 2017), while hydrochlordecones (family A) were the only products in presence of zero-valent iron (Belghit et al., 2015). Combining vitamin $B_{12}$ and a reducing agent generated practically a similar pattern of chlordecone TPs as those observed in Citrobacter sp.86 or Desulfovibrio sp.86 anaerobic cultures (Chevallier et al., 2019; Della-Negra et al., 2020). However, comparison of the carbon isotope fractionation of chlordecone in microbiological degradation using Citrobacter sp.86 and in chemical degradation mediated by vitamin $B_{12}$ suggested different mechanistic pathways (Chevallier et al., 2018).

Genome sequence analysis of Citrobacter sp.86 revealed that this facultative anaerobic bacterium harbors the complete anaerobic cobalamin synthesis pathway (Chaussonnerie et al., 2016). As none of the key enzymes involved in organohaliderespiration (reductive dehalogenases) were detected in the Citrobacter sp.86 genome sequence (van der Ploeg et al., 1991; Nagata et al., 2007; Fincker and Spormann, 2017), it was hypothesized that cobalamin and/or other corrinoids might be involved. To investigate this hypothesis, knockout mutants of Citrobacter sp.86 were constructed in which cobalamin synthesis was impaired. These mutant strains, that had one or more genes deleted, were tested for their ability to promote chlordecone degradation, in comparison with the Citrobacter sp.86 wild-type.

More than 40 years ago, another Citrobacter species (Citrobacter freundii) was described to anaerobically degrade a different chlorinated pesticide: lindane (Figure 1), also known as $\boldsymbol{\gamma}$-hexachlorocyclohexane, $\boldsymbol{\gamma}$-HCH (Jagnow et al., 1977). 
As for the transformation of chlordecone by Citrobacter sp.86, this transformation seemed to be co-metabolic. Lindane, toxic for humans and other organisms, has been widely used over the last 7 decades for agricultural, veterinary, and even human sanitary usages as a pesticide, wood protector, or against scabies and lice, generating millions of tons of waste over a wide range of countries (Middeldorp et al., 1996; Lal et al., 2010; Álvarez et al., 2012; Vijgen et al., 2019; Wacławek et al., 2019). The hydrophobicity and chemical stability of lindane, with half-life in soil and water spanning years, its ongoing use in some countries as well as the existence of stockpiles also designate it as a legacy organochlorine compound; and it is still detected in environmental compartments (Laquitaine et al., 2016; Saez et al., 2017; Vijgen et al., 2019). Lindane was also frequently used in the FWI before being largely replaced by chlordecone, and ultimately banned in 2009 due to its recalcitrance to degradation and toxicity (Nolan et al., 2012; Dereumeaux et al., 2019).

Different bacterial consortia or single bacteria isolated from soils, sediments, plants, or farm fields have been described for their ability to degrade lindane aerobically (Lal et al., 2006, 2010; Saez et al., 2017; Zhang et al., 2020). Under these conditions, the aerobic degradation relies on the presence of the linA-E genes, which encode among others a dehydrochlorinase and a haloalkane dehalogenase providing chlorinated benzene derivatives followed by the lin F-J genes that ultimately fuel them up into the central metabolism (Senoo and Wada, 1989; Kumari et al., 2002; Dogra et al., 2004; Böltner et al., 2005; Endo et al., 2005; Lal et al., 2010; Cuozzo et al., 2017). Lindane partial degradation has also been observed in some Guadeloupean soils where it was suggested that lindane aerobic degradation could occur, probably through bacteria closely related to the family Sphingomonadaceae (Laquitaine et al., 2016).

Citrobacter sp.86 is a facultative anaerobe, but its genome does not encode homologs of the lin genes. Co-metabolic anaerobic degradation of lindane was reported for facultative anaerobic bacteria like C. freundii (Jagnow et al., 1977) but also for strict anaerobes like a Clostridium sp., Desulfovibrio gigas and Desulfococcus multivorans (Macrae et al., 1969; Ohisa and Yamaguchi, 1978; Boyle et al., 1999; Badea et al., 2009; Mehboob et al., 2013), in bacterial consortia (Qiao et al., 2020; Zhang et al., 2020) and finally using slurry systems (Quintero et al., 2005; Robles-González et al., 2008; Camacho-Pérez et al., 2012). In 2011, an anaerobic enrichment culture was showed to use lindane as electron acceptor; however, no organohaliderespiring bacteria were detected in the consortium (Elango et al., 2011). In 2018, two Dehalococcoides mccartyi strains (195 and BTF08) were also found to use lindane as an electron acceptor (Bashir et al., 2018). In contrary to the aerobic degradation pathway of lindane, two mechanisms were proposed in anaerobiosis. The first one involved two successive dichloroeliminations followed by a dehydrochlorination leading to chlorobenzene. The second one passes through a pentachlorocyclohexene intermediate to finally form 1,2-dichlorobenzene and 1,3-dichlorobenzene (Figure S1). Benzene was also observed in several conditions (Zhang et al., 2020).
However, to date, no genes or enzymes were found to be involved in these dechlorination processes (Lal et al., 2010; Zhang et al., 2020). The main goal of the present study was to elucidate whether the corrinoids produced by Citrobacter sp.86 play a role in the chlordecone and lindane biotransformations.

\section{MATERIALS AND METHODS}

\section{Chemicals}

Chlordecone was obtained from Azur Isotopes (purity 98\%). Chemical products used for microbiological media, vitamin $\mathrm{B}_{12}(>98 \%)$, chloro(pyridine)cobaloxime(III), lindane (97\%), 1,3-dichlorobenzene (98\%), 1,4-dichlorobenzene (99\%), chlorobenzene (99.8\%), and benzene (99.8\%) were obtained from Sigma Aldrich. Titanium (III) citrate was prepared from titanium (III) chloride ( $>12 \%$ in $\mathrm{HCl}$; Sigma Aldrich) and sodium citrate and neutralized with $\mathrm{Na}_{2} \mathrm{CO}_{3}$ (Chevallier et al., 2019). Dichloromethane (HPLC grade) was obtained from Fisher Chemical.

\section{Construction of Citrobacter sp.86 Knockout Mutant Strains}

Knockout mutant strains in Citrobacter sp.86 were constructed using the $\lambda$-red recombinase technique as developed for Escherichia coli (Datsenko and Wanner, 2000) with some modifications. Briefly, a PCR product was generated by using primers with 50 -nt 5 -extensions that are homologous to regions adjacent to the gene to be inactivated and 20-nt 3'-extremities hybridizing to the antibiotic resistance cassette of the plasmid pKD3 (chloramphenicol resistance cassette) or pKD4 (kanamycin resistance cassette). The amplicon was purified (QIAquick PCR Purification Kit, Qiagen) and introduced by transformation in electrocompetent Citrobacter sp.86 cells which harbor the helper plasmid pKD46-Gm (Doublet et al., 2008; kindly provided by Benoit Doublet). The thermosensitive plasmid pKD46-Gm contains the Red recombinase genes located under an L-arabinose inducible promoter and the gentamicin resistance cassette. Recombinant cells were selected on LB-agar plates containing the appropriate antibiotic (kanamycin or chloramphenicol, $50 \mu \mathrm{g} / \mathrm{ml}$ ). The effective replacement of the target gene with the resistance cassette was verified by PCR-amplifying the targeted chromosomal locus of wild-type strain and of the recombinant candidates using specific primers located $200 \mathrm{nt}$ upstream and downstream of the target gene and analyzing the PCR products by electrophoresis on agarose gels. The primer sequences used in this study are given in Tables S1, S2, and the designation and genotype of all bacterial strains as well as plasmids used in this study are given in Tables S3, S4.

\section{Culture Conditions}

Citrobacter sp.86 strains were kept frozen at $-80^{\circ} \mathrm{C}$ as stock glycerol (15\%). Before starting phenotyping or degradation experiments, the bacteria were first grown aerobically at $37^{\circ} \mathrm{C}$ on LB plates with $100 \mu \mathrm{g} / \mathrm{ml}$ carbenicillin (the Citrobacter sp.86 genome encodes a beta-lactamase), and isolated colonies were used as inoculum. 
For analysis of growth requirements (phenotyping), the Citrobacter sp.86 wild-type and mutant colonies issued from LB agar plates were then spread onto agar plates containing mineral medium MM previously described (Chaussonnerie et al., 2016) but without vitamin $B_{12}$, supplemented with glucose $(20 \mathrm{mM})$ or pyruvate $(40 \mathrm{mM})$. When indicated, vitamin $B_{12}$ and L-methionine were added at a final concentration of $0.3 \mu \mathrm{M}$ or $0.3 \mathrm{mM}$, respectively. Plates were incubated aerobically at $37^{\circ} \mathrm{C}$. For anaerobic assays, colonies issued from aerobic MM plates supplemented with methionine but without vitamin $\mathrm{B}_{12}$ were spread on $\mathrm{MM}$ plates containing $\mathrm{Na}_{2} \mathrm{~S}(0.4 \mathrm{~g} / \mathrm{L})$, glucose $(20 \mathrm{mM})$, or pyruvate $(40 \mathrm{mM})$, with or without vitamin $\mathrm{B}_{12}$, and incubated at room temperature $(\mathrm{rt})$ in a glove box (Unilab mBraun), under an $\mathrm{N}_{2} / \mathrm{H}_{2}(98 / 2 ; \mathrm{V} / \mathrm{V})$ atmosphere.

Anoxic microbial incubations (degradation experiments) were performed in the glove box in daylight. Microbial liquid cultures were carried out in the mineral medium MM, but without vitamin $B_{12}$, supplemented with pyruvate $(40 \mathrm{mM})$ as carbon source, $2 \mathrm{~g} / \mathrm{L}$ yeast extract, and $2 \mathrm{~g} / \mathrm{L}$ tryptone. This complemented mineral medium was named MMpyt. The reductant was $\mathrm{Na}_{2} \mathrm{~S}(0.4 \mathrm{~g} / \mathrm{L})$, and $0.1 \%$ of resazurin was added as an indicator of anaerobiosis. When indicated, it was adjusted at a $\mathrm{pH}$ differing from the standard $(\mathrm{pH}$ 7.0) by varying the proportions of the buffering system $\left(\mathrm{KH}_{2} \mathrm{PO}_{4} / \mathrm{K}_{2} \mathrm{HPO}_{4}\right)$. Chlordecone and lindane were solubilized in dimethylformamide to a $200 \mathrm{mg} / \mathrm{ml}$ stock solution and used at $40 \mu \mathrm{g} / \mathrm{ml}$ or $20 \mu \mathrm{g} / \mathrm{ml}$, respectively.

After growth on LB plates, a colony of each Citrobacter sp.86 strain resuspended in $50 \mu \mathrm{l} \mathrm{NaCl} 0.8 \%$ was transferred in the anaerobic glove box (Figure S2) and used for initial inoculation of a $2 \mathrm{ml}$ culture in MMpyt with $100 \mu \mathrm{g} / \mathrm{ml}$ carbenicillin (culture C1). After $24 \mathrm{~h}, 50 \mu \mathrm{l}$ of $\mathrm{C} 1$ was used to inoculate a $5 \mathrm{ml}$ culture in MMpyt with $100 \mu \mathrm{g} / \mathrm{ml}$ carbenicillin and $10 \mu \mathrm{g} / \mathrm{ml}$ chlordecone or $10 \mu \mathrm{g} / \mathrm{ml}$ lindane (culture $\mathrm{C} 2$ ). After $24 \mathrm{~h}, \mathrm{C} 2$ was finally used to inoculate a $50 \mathrm{ml}$ culture in MMpyt and $40 \mu \mathrm{g} / \mathrm{ml}$ chlordecone or $20 \mu \mathrm{g} / \mathrm{ml}$ lindane (culture C3, contained in $100 \mathrm{ml}$ glass serum vials), which was incubated for 4 months and 28 days for chlordecone and lindane, respectively. Each degradation experiment was done in duplicate. All experiments were monitored over time using GC-MS techniques. A negative control vial (without bacteria) was added to each tested condition.

\section{Organochlorines Sampling/Extraction for Chlordecone or Lindane Microbiological Culture Monitoring}

Chlordecone monitoring was performed using GC-MS. After homogenization of the liquid cultures, $500 \mu \mathrm{l}$ were collected and extracted twice using $250 \mu \mathrm{l}$ isooctane. The combined organic layers were then analyzed through GC-MS analysis via liquid injection.

For lindane monitoring Headspace GC-MS (HS-GC-MS) was required. In this case, $700 \mu$ l of culture were sampled and put into a Chromacol 10-HSV vial of $10 \mathrm{ml}$ (Agilent). The headspace gas was then analyzed through the Headspace tool (see below).

\section{Analytics}

Gas Chromatography coupled to Mass Spectrometry analyses were used for chlordecone degradation monitoring and were carried out using a Thermo Fisher Focus GC coupled to a single-quadrupole mass spectrometer (Thermo Fisher DSQ II). The instrument was equipped with a non-polar $30 \mathrm{~m} \times 0.25 \mathrm{~mm} \times 0.25 \mu \mathrm{m}$ DB-5MS column (Agilent J\&W) and a split/splitless injector. Ionization conditions and the GC program have been described elsewhere (Chevallier et al., 2019).

Gas Chromatography Mass Spectrometry coupled with a Headspace trap (HS-GC-MS) analyses were used for lindane degradation monitoring and were performed on a Thermo Fisher Trace 1300 coupled to an ISQ 7000 VPI single quadrupole mass spectrometer. The instrument was equipped with a $30 \mathrm{~m} \times 0.25 \mathrm{~mm} \times 0.25 \mu \mathrm{m}$ DB-624-UI column (Agilent J\&W), a split/splitless injector, and an automatic sampler TriPlus $\mathrm{RSH}$ coupled to a HeadSpace tool. For MS analyses, the following standard working conditions were applied: electronic impact ionization, positive mode detection, ion source at $220^{\circ} \mathrm{C}$, detector voltage $70 \mathrm{eV}$, and full scan mode $\mathrm{m} / \mathrm{z} 33-300$ (scan time $0.20 \mathrm{~s}$ ). Injection and transfer line temperatures were set up at 200 and $280^{\circ} \mathrm{C}$, respectively. Monitoring vials were incubated for $5 \mathrm{~min}$ at $50^{\circ} \mathrm{C}$ and sampled with a syringe at $50^{\circ} \mathrm{C}$. One milliliter of the headspace gas was injected each time at a filling speed of $10 \mathrm{ml} / \mathrm{min}$, an injection speed of $10 \mathrm{ml} / \mathrm{min}$, and a penetration speed of $10 \mathrm{ml} / \mathrm{s}$. The splitless injection mode was applied at $150^{\circ} \mathrm{C}$. Carrier gas was helium at a constant flow rate of $0.5 \mathrm{ml} / \mathrm{min}$. The GC program started at $30^{\circ} \mathrm{C}$ (hold time $6 \mathrm{~min}$ ), continued with $15^{\circ} \mathrm{C} / \mathrm{min}$ to $130^{\circ} \mathrm{C}$ (hold time $0.5 \mathrm{~min}$ ), followed by $7^{\circ} \mathrm{C} \mathrm{min}^{-1}$ to $250^{\circ} \mathrm{C}$ (hold time $10 \mathrm{~min}$ ).

\section{Chemical Transformation of Chlordecone With Vitamin $\mathbf{B}_{12}$ or Cobaloxime}

According to the protocol described elsewhere (Chevallier et al., 2019), to a solution of chlordecone $\left(5.0 \mathrm{mg}, 9.910^{-6} \mathrm{~mol}\right.$, and 1 eq.) and vitamin $B_{12}\left(4.1 \mathrm{mg}, 3.010^{-6} \mathrm{~mol}\right.$, and 0.3 eq.) or cobaloxime (1.2 mg, $3.010^{-6} \mathrm{~mol}$, and 0.3 eq.) in degassed water $(30 \mathrm{ml})$ was added titanium (III) citrate basified to $\mathrm{pH}$ 12 with $\mathrm{NaOH}$ ( $3 \mathrm{M} ; 5 \mathrm{ml}, 3.310^{-4} \mathrm{~mol}$, and 32 eq.). The reaction mixtures were stirred under $\mathrm{N}_{2}$ atmosphere at $\mathrm{rt}$ for $2 \mathrm{~h}$; and monitored by GC-MS.

\section{RESULTS AND DISCUSSION}

\section{Strategy for the Targeted Deletion of Cobalamin Biosynthesis Genes in Citrobacter sp.86}

Since most genes predicted to operate in a cobalamin biosynthesis pathway are clustered (Figure 2A), we chose to construct a test-set of mutant strains by targeted deletion of genomic coding regions encompassing multiple genes. In fact, these multiple gene deletions would certainly result in a defective cobalamin. Three mutant types were designed affecting different steps of the cobalamin molecule construction: (i) the insertion of the 


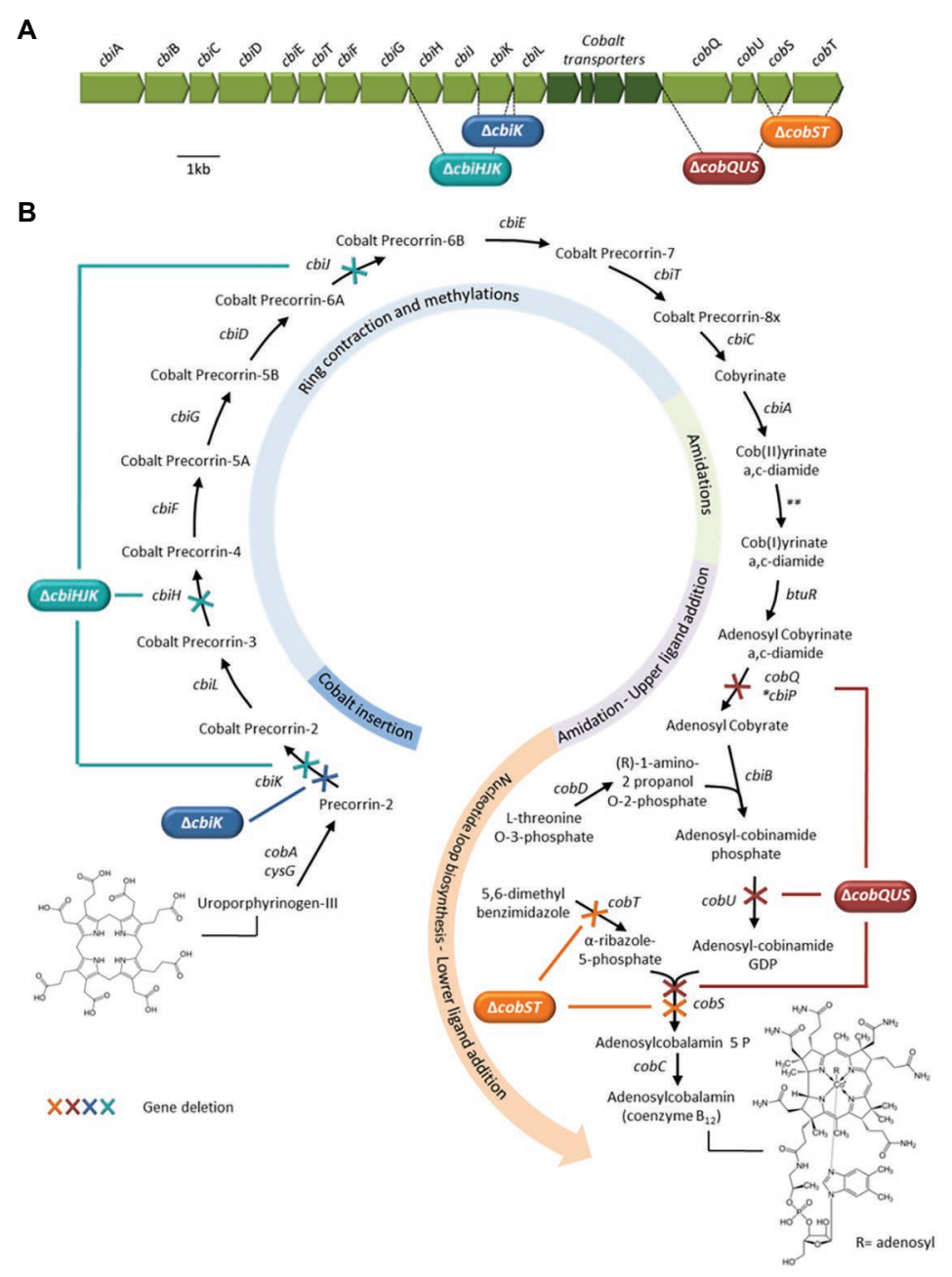

FIGURE 2 | (A) Genetic organization of the main Citrobacter sp.86 anaerobic cobalamin biosynthesis gene cluster. The regions targeted for the deletion of one to three consecutive genes and replacement with an antibiotic resistance marker gene - see section the Materials and Methods - are shown. (B) Anaerobic cobalamin biosynthesis pathway in Citrobacter sp.86 based on genome annotation ( ${ }^{*} c b i P$, synonym name for cobQ). Reactions blocked in the mutant strains are shown by crosses. ${ }^{* *}$ In the anaerobic pathway, there is no dedicated enzyme for cobalt reduction (Fonseca and Escalante-Semerena, 2000).

cobalt atom into the corrin ring and corrin core functionalization, (ii) the corrin core functionalization and nucleotide loop biosynthesis, and (iii) the nucleotide loop biosynthesis including the lower ligand insertion. They were respectively obtained by deleting the following gene combinations: cbiHJK, cobQUS, and cobST. In addition, based on preliminary results obtained for the Citrobacter sp. $86 \triangle c b i H J K$ strain, a fourth mutant type cbiK affecting the cobalt insertion was constructed (Figure 2B). Detailed reactions catalyzed by proteins encoded by these genes are shown in Figure S3.

\section{Knockout Mutant Phenotypes}

There are two methionine synthases in Citrobacter sp.86, one cobalamin-independent encoded by the gene metE and the other cobalamin-dependent, encoded by the gene metH. On a $\Delta$ metE background, a deletion that would impact the biosynthesis of cobalamin in Citrobacter sp.86 would have an effect on its viability. In a first step, we decided to test our constructions on this background.

Prototrophy of a metE knockout mutant strain in mineral medium and in the absence of any nutritional supplement other than a carbon source (glucose or pyruvate) was used as a physiological phenotypic indicator of the cellular cobalamin production. In the four $\Delta m e t E$ and $\Delta c o b / c b i$ double mutant strains, we hypothesized that rescue of methionine auxotrophy would be achieved by exogenous cobalamin.

The growth phenotype of all strains was tested on solid rich or mineral medium under both aerobic and anaerobic conditions. Independently, all genotypes were also checked by PCR (Figure S4A).

As shown in Table S5, no growth defects were observed for any strain on LB rich medium, but growth phenotypes were more contrasted on mineral medium (Table S5; Figures S4B,C). The Citrobacter sp.86 $\Delta$ metE strain did not 
grow under aerobic conditions and this defect was alleviated by supplying exogenous cobalamin, which is required as a cofactor for MetH. In contrast, it grew under anaerobic conditions in the absence of any nutritional supplement indicating successful endogenous cobalamin biosynthesis. So, we concluded that Citrobacter sp.86 was unable to synthesize cobalamin under aerobic conditions. These results were consistent with the annotation of the genes involved in the anaerobic cobalamin pathway. Similarly, the enteric bacterium Salmonella typhimurium also synthesizes cobalamin de novo only under anaerobic growth conditions (Jeter et al., 1984).

The four Citrobacter sp.86 double mutant $(\Delta$ metE and $\Delta c o b / c b i)$ strains were unable to grow on mineral medium under anaerobiosis, indicating that incomplete corrinoids cannot functionally replace the cobalamin cofactor for MetH functionality. Under these conditions, exogenous cobalamin fulfills this requirement. These results confirm the impairment of the cobalamin biosynthetic pathway in all cob/cbi knockout mutant strains made in this study.

In a second step, we also constructed four $\Delta c o b$ or $\Delta c b i$ Citrobacter sp.86 knockout mutant strains to test for their ability to degrade chlordecone and lindane compounds. Based on the results of genotype verification by PCR and the physiological consequences of the cobalamin biosynthesis pathway disruption described above, these strains are impaired in the cobalamin synthesis pathway. None of these deletions impacts growth of Citrobacter sp.86 on mineral medium in the absence of cobalamin (Table S5; Figure S5; Supplementary Material), indicating that production of incomplete non-functional corrinoids was not harmful for the bacteria. Incubation of all these strains with chlordecone or lindane did not modify their growth phenotype (Figure S5; Supplementary Material).

\section{Chlordecone Transformation by Citrobacter sp.86 Wild-Type and Mutant Strains}

The wild-type Citrobacter sp.86 and the test-set of cobalamin biosynthesis pathway mutant strains were incubated with chlordecone in MMpyt medium. Under these laboratory conditions, the wild-type strain reached the stationary-phase after $10 \mathrm{~h}$. In reported bacterial transformations of chlordecone (Chevallier et al., 2019), the appearance of A and B TP families (monitored using GC-MS) systematically went along with C family (detected using LC-MS) while chlordecone disappearance was completed after several months. Here, we only focused on the detection of A and B families using GC-MS analysis. Transformation profiles of chlordecone in cultures were monitored regularly by GC-MS over a 4-month period. Interestingly, Citrobacter sp.86 and the mutant strains $\Delta$ cobQUS and $\Delta$ cobST showed the same chlordecone transformation profile (Figure 3; Supplementary Material): upon chlordecone incubation, trace amounts of $\mathrm{B} 1$ were detected on the 7 th day. After 21 days, B1 was the main chlordecone TP detected using GC-MS analysis, as expected (Chaussonnerie et al., 2016; Chevallier et al., 2018, 2019). The transformation did not occur while the cells were actively growing but rather mostly after entry into the lysis phase (Figure S5). On the other hand,
Citrobacter sp.86 $\Delta c b i H J K$ and $\Delta c b i K$ did not transform chlordecone even after an additional extensive period of incubation (a total period of 201 days, Supplementary Material), just as in the negative control without bacteria. In the light of these results, it can be assumed that suppression of the corrinoid lower ligand or modifications of the corrin core patterns do not affect the ability of Citrobacter sp.86 to degrade chlordecone. In contrast, inactivating the cobalt insertion step prevents chlordecone degradation, confirming the involvement of cobalamin or other corrinoids in chlordecone transformation. However, the corrinoids, which are functional for the chlordecone degradation process, are not necessarily complete cobalamin in contrast to the functional cofactor involved in enzymatic reactions. All these results are consistent with a transformation of chlordecone by a non-enzymatic process involving corrinoids with an inserted cobalt atom. So far, no mechanism can assess how cobalamin would react with chlordecone. However, assuming that chlordecone transformation would be the result of the action of corrinoids released by Citrobacter sp.86, the formation of a $\mathrm{Co}-\mathrm{C}$ bond linking the bishomocubane cage to the corrinoid could be inferred. It is likely that a $\mathrm{Co}(\mathrm{I})$ oxidation state would be needed to enable the chlordecone attack (Schrauzer and Katz, 1978). In 1978, Schrauzer and Katz apparently detected [Co] $-\mathrm{C}_{3} \mathrm{Cl}_{3} \mathrm{H}_{2}$ fragments within the abiotic reaction mixture of chlordecone with vitamin $\mathrm{B}_{12}$, supporting this assumption.

In addition, it is known that several chemical transformations of chlordecone involving vitamin $\mathrm{B}_{12}$ reduced under a $\mathrm{Co}(\mathrm{I})$ oxidation state by strong reducing agents generate the same TP profile (Schrauzer and Katz, 1978; Ranguin et al., 2017; Chevallier et al., 2018, 2019). In our hands, use of chloro(pyridine) cobaloxime, known to be a good model of vitamin $\mathrm{B}_{12}$ (Schrauzer and Katz, 1978; Terán et al., 2018; Pizarro et al., 2019) also led to the same diversity of chlordecone TPs in presence of a strong reducing agent (Figure S6). It supports the hypothesis that several cobalt complexes containing a corrin ring could afford the same chlordecone TPs, once reduced.

The present results show that microbial degradation of chlordecone mediated by Citrobacter sp.86 is clearly correlated to the production of cobalamin derivatives. Chemical degradation using vitamin $\mathrm{B}_{12}$ or cobaloxime in aqueous solution also leads to the same TPs (Schrauzer and Katz, 1978; Jablonski et al., 1996; Ranguin et al., 2017; Chevallier et al., 2018, 2019). Taken together, these observations suggest that microbial and chemical degradations share strong similarities in their mechanistic pathway. These conclusions are apparently not supported by some of our previous findings obtained from carbon specific isotope analysis (CSIA). Indeed, the carbon isotopic enrichment factors observed for microbiological and vitamin $B_{12}$-mediated degradations differed significantly, suggesting two distinct mechanisms (Chevallier et al., 2018). However, the strong $\mathrm{pH}$ variation $(\mathrm{pH} 7$ for microbiological cultures and $\mathrm{pH} 12$ for chemical conditions) could also explain the difference in the ${ }^{13} \mathrm{C}$ isotopic signatures. For instance, Heckel and co-workers observed that a change from acidic to basic conditions led to a switch in dechlorination mechanisms during the chemical degradation of trichloroethene mediated by vitamin $\mathrm{B}_{12}$ reduced under a Co(I) state (Heckel et al., 2018). 

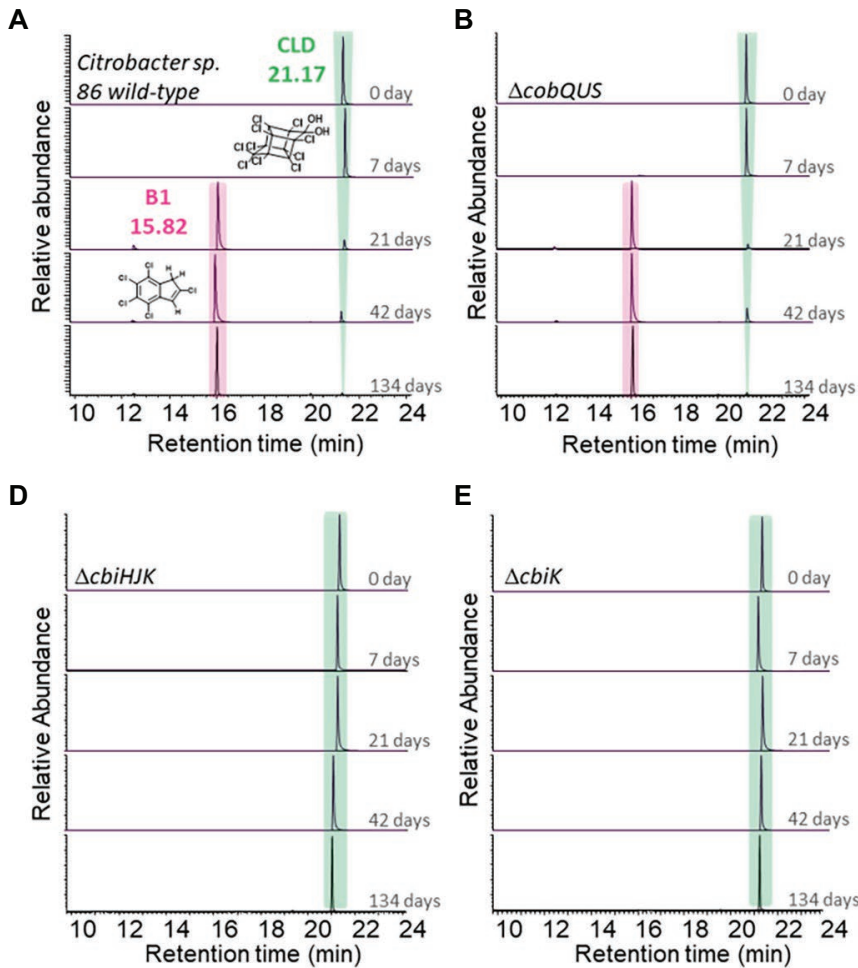

E

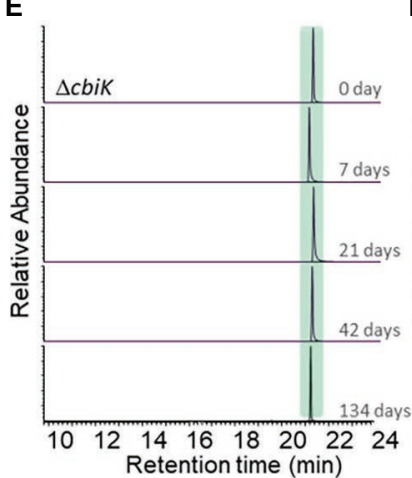

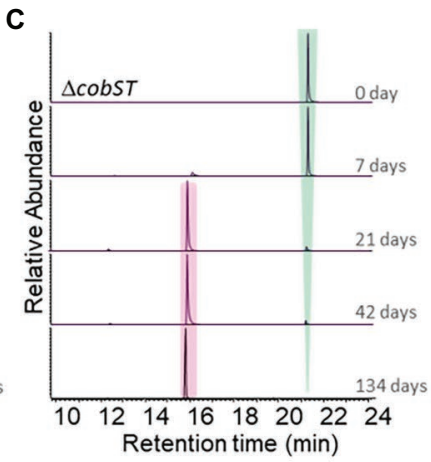

$\mathbf{F}$

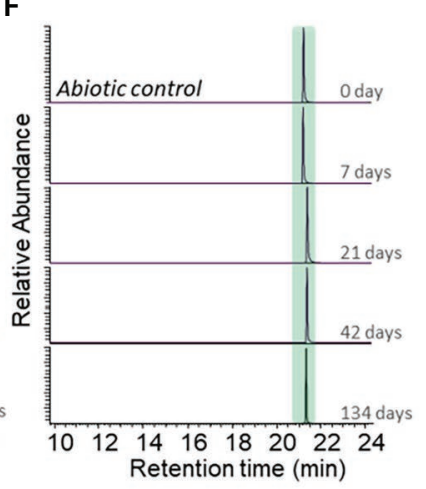

FIGURE 3 | Transformation of chlordecone in Citrobacter sp.86 wild-type and mutant strain cultures over the time. GC-MS chromatograms (full scan mode) of extracted cultures at selected times incubated with (A) Citrobacter sp.86 wild-type, (B) $\Delta$ cobQUS mutant strain, (C) $\Delta$ cobST mutant strain, (D) $\Delta c b i H J K$ mutant strain, (E) $\Delta$ cbik mutant strain, and (F) without bacteria (abiotic control). Numeric data of peak areas are available in Supplementary Material. The various mutant strains and the negative control (abiotic control) were incubated under the same conditions. For more clarity, a single chromatogram is displayed among the duplicates for each selected time.

Furthermore, it is possible that biologically produced corrinoids could also be responsible for chlordecone degradation performed by anaerobic bacteria and archaea described in other studies. Thereby, the chlordecone degradation by the methanogen $M$. thermophila seemed to be mediated by corrinoids (Jablonski et al., 1996). Interestingly, consortia 86 and 92 able to degrade chlordecone contained, among others, Desulfovibrio, Pleomorphomonas, and Sporomusa species, possessing cobalamin biosynthesis genes (Chaussonnerie et al., 2016). Among these bacteria, Desulfovibrio sp. 86 was isolated and showed to degrade chlordecone along with the same TPs profile as observed in presence of Citrobacter sp.86 (Della-Negra et al., 2020). In the same way, in microcosms amended with chlordecone, no known obligate organohalide respiring bacteria were observed, whereas enrichment with Desulfovibrio, Sporomusa, and Geobacter species or methanogens were noticed (Lomheim et al., 2020). Still, in this case, these bacteria and archaea could be corrinoid-producers.

\section{Lindane Transformation by Citrobacter sp.86 Wild-Type and Mutant Strains}

Lindane ( $\gamma$-hexachlorocyclohexane) dechlorination by C. freundii under anaerobic conditions has been already described (Jagnow et al., 1977). Remarkably, as it is the case for the degradation of chlordecone by Citrobacter sp.86, it was noticed that dechlorination of lindane may not be related to C. freundii growth. In this context, we tested whether Citrobacter sp.86, which is a different species than C. freundii, was intrinsically able to dechlorinate lindane and if this dechlorination was mediated by cobalamin or corrinoids.

Under the same incubation conditions as for chlordecone, in another set of experiments, lindane did not impede the growth of Citrobacter sp.86 (Figure S5). Lindane degradation was observed with the concomitant formation of benzene and chlorobenzene as major TPs, (Figure 4). Trace level of $\gamma$-tetrachlorocyclohexene was also detected during lindane degradation operated by Citrobacter sp.86 (Supplementary Material). After 28 days, no more lindane in the culture was detected by HS-GC-MS. In contrast, after 42-day incubation, chlordecone was still detected by GC-MS analysis (Figure 3). The higher solubility in water of lindane $\left(7-9 \mathrm{mg} / \mathrm{L}\right.$ at $25^{\circ} \mathrm{C}$ and $\mathrm{pH} 7$, Saley et al., 1982) compared to chlordecone $\left(1-2 \mathrm{mg} / \mathrm{L}\right.$ at $25^{\circ} \mathrm{C}$ and $\mathrm{pH} 7$, Dawson et al., 1979) may account for its higher degradability (at the same molar ratio) by the Citrobacter sp.86 cultures.

Chlorobenzene, benzene, and/or $\gamma$-tetrachlorocyclohexene have already been described as TPs observed in anaerobic degradation of lindane by $C$. freundii, sulfate-reducing bacteria including D. gigas, D. multivorans, and also in bacterial consortia 

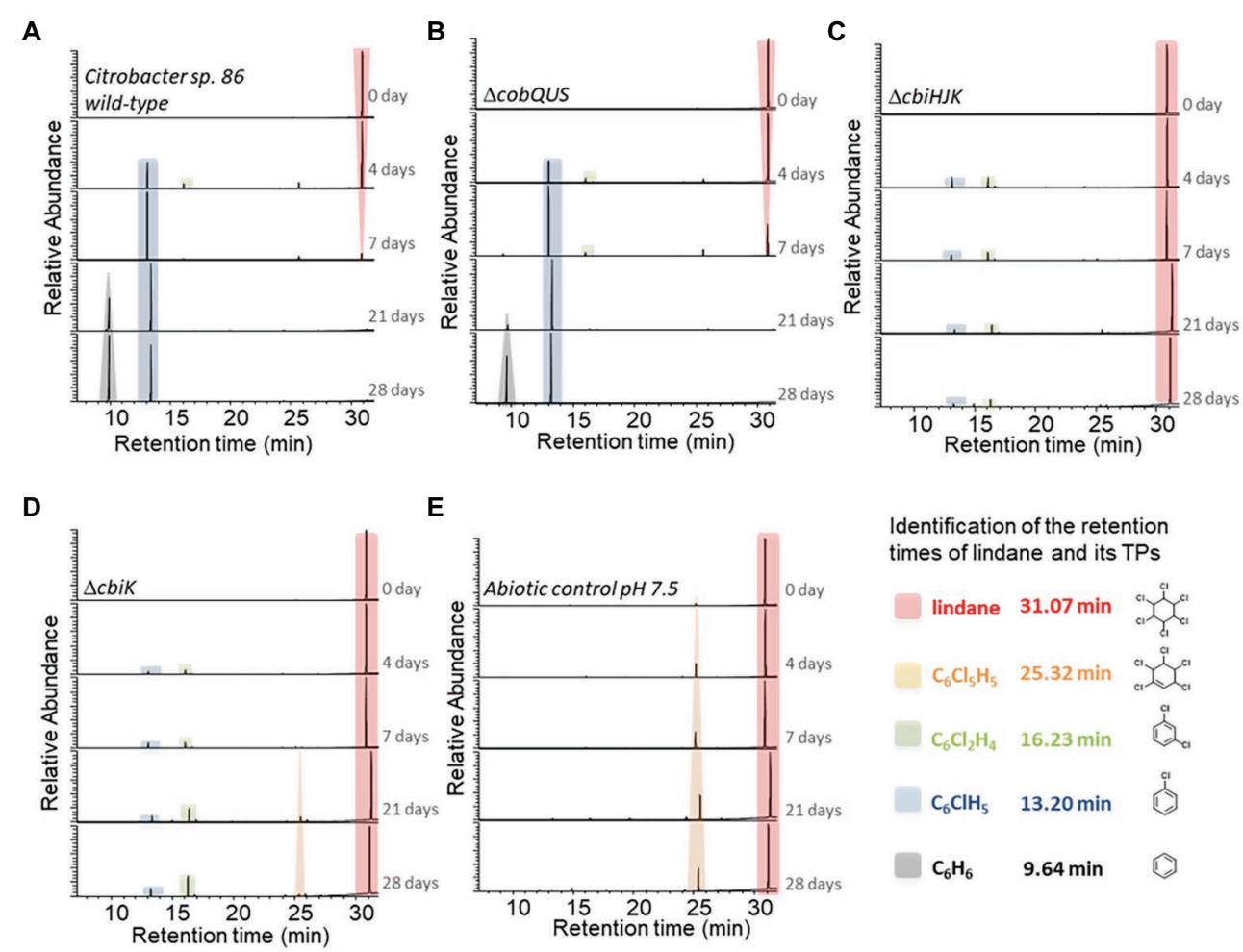

E
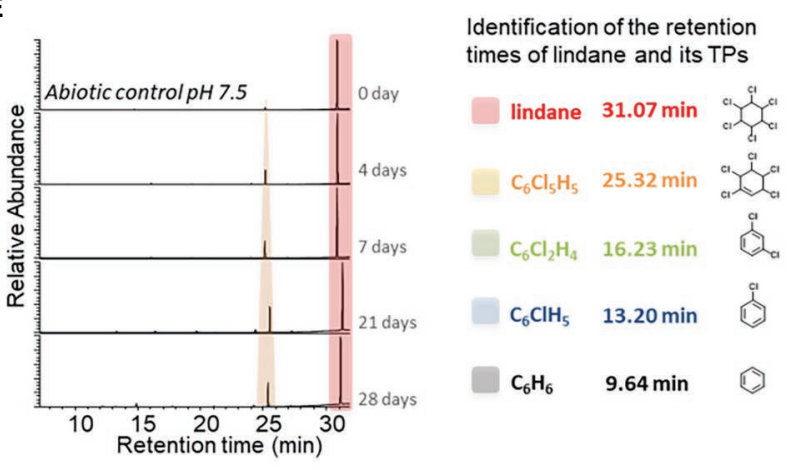

FIGURE 4 | Transformation of lindane in Citrobacter sp.86 wild-type and mutant strain cultures over the time. HS-GC-MS extracted ion chromatograms ( $\mathrm{m} / \mathrm{z}=181,147,146,112$, and 78, searched for each condition) of sampled cultures at selected times incubated with (A) Citrobacter sp.86 wild-type,

(B) $\triangle c$ cobQUS mutant strain, (C) $\Delta c b i H J K$ mutant strain, (D) $\Delta c$ cbiK mutant strain, and (E) without bacteria (abiotic control). Numeric data of peak areas are available in Supplementary Material. The various mutant strains and the negative control (abiotic control) were incubated under the same conditions. For more clarity, a single chromatogram is displayed among the duplicates at each selected time.

enriched in Pelobacter (Jagnow et al., 1977; Boyle et al., 1999; Badea et al., 2009; Qiao et al., 2020). It is likely that these TPs appeared by a two-step process involving two sequential dichloroelimination reactions, followed by another dichloroelimination to produce benzene or a hydrodechlorination to generate chlorobenzene (Zhang et al., 2014; Qiao et al., 2020; Figure S1B). After C. freundii (Jagnow et al., 1977), Citrobacter sp.86 is the second species of this genus reported to degrade lindane, and this degradation most likely occurs in the same way as in other anaerobic bacteria. These bacteria dechlorinate lindane cometabolically, with for instance glucose, lactate, or pyruvate as suitable carbon sources.

We also observed that Citrobacter sp.86 $\Delta$ cobQUS degraded lindane just like the wild-type (Figure 4B). In contrast, Citrobacter sp.86 $\Delta$ cbiHJK and Citrobacter sp.86 $\Delta c b i K$ were unable to quantitatively dechlorinate lindane (Figures 4C,D). Low levels of chlorobenzene and 1,3-dichlorobenzene as well as trace amount of 1,3,4,5,6-pentachlorocyclohex-1-ene were observed, but GC-MS peak areas were insignificant compared to the Citrobacter sp.86 wild-type strain and $\Delta$ cobQUS mutant strain. In comparison, abiotic controls showed a significant formation of 1,3,4,5,6-pentachlorocyclohex-1-ene while lindane remained definitely predominant after 28 days. This TP has been previously reported during the photolysis of lindane (Zaleska et al., 2000). As all degradation experiments were performed in daylight, we assumed that an additional slow photodegradation process was taking place. The rate of photodegradation would depend on the prevalence of other competing degradation pathways.

An additional abiotic $\mathrm{pH}$-dependence study of lindane dechlorination showed that 1,3,4,5,6-pentachlorocyclohex-1-ene, 1,3-dichlorobenzene, and chlorobenzenewere spontaneously produced, albeit at low rate, when the $\mathrm{pH}$ of the incubation medium was set at more basic values $(\mathrm{pH} \geq 8)$, as it has already been described (Figure 5; Hiskia et al., 1997). The possible photodegradadation process and the $\mathrm{pH}$-dependent degradation phenomenon could also explain the detection of 1,3-dichlorobenzene and chlorobenzene in mutants Citrobacter sp.86 $\Delta$ cbiHJK and Citrobacter sp.86 $\Delta c b i K$.

These results show that corrinoids synthesized by Citrobacter sp.86 as well as Citrobacter sp.86 $\Delta$ cobQUS are involved in the most prominent lindane degradation pathway. As for chlordecone, a complete cobalamin molecule was not needed for lindane degradation. Also, by abiotic processes, Marks et al. (1989) showed high activity of lindane dechlorination by cobinamides reduced with dithiothreitol. In their work, the authors tested a variety of porphyrins and corrins for catalysis of lindane dehalogenation. They showed the importance of the cobalt ion in the tetrapyrrole ring. Also, dehalogenation activity of cobinamides was about 8 -fold higher than that of cobalamin. These authors suggested that the lower ligand could 


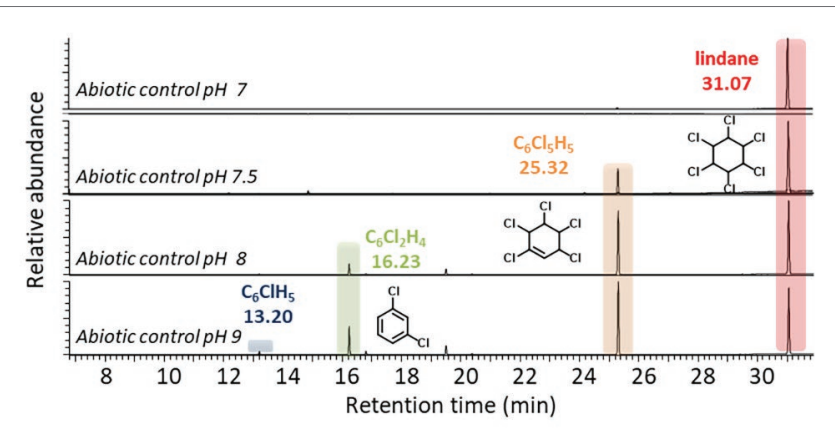

FIGURE 5 | Abiotic transformation of lindane in neutral and basic conditions. HS-GC-MS extracted ion chromatograms ( $\mathrm{m} / \mathrm{z}=181,147,146,112$, and 78 , searched for each condition) after 21 days of abiotic cultures at different $\mathrm{pH}: 7,7.5,8$, and 9 . Numeric data of peak areas are available in Supplementary Material.

sterically hinder the approach of lindane to the cobalt ion at the center of the corrin ring. It could also be that the absence of the lower base coordination results in an increase of the oxido-reduction potential of cobinamide compared to cobalamin, which becomes easier to reduce (Dereven'kov et al., 2016).

Finally, we postulate that the implication of corrinoids, synthesized by Citrobacter sp.86, in lindane dechlorination as shown in this study could be extended not only to C. freundii but also to other bacteria that anaerobically degrade lindane such as D. gigas, D. multivorans, and Clostridium (Macrae et al., 1969; Jagnow et al., 1977; Ohisa and Yamaguchi, 1978; Boyle et al., 1999; Badea et al., 2009; Mehboob et al., 2013). In the same way, corrinoids could be involved in lindane degradation by consortia with the enrichment of Pelobacter within the dehalogenation process (Qiao et al., 2020). All these bacteria (i) are fermenters, (ii) transform lindane co-metabolically, and (iii) seem to be able to produce cobalamin (Roth et al., 1996; Shelton et al., 2019).

\section{Targeting Microbial Corrinoids as Specific Tools for Organochlorine Pesticides Degradation}

Under abiotic conditions, involvement of corrinoids in transformation and dechlorination of compounds including chlordecone and lindane has been well-documented (Schrauzer and Katz, 1978; Marks et al., 1989; Jablonski et al., 1996; Rodríguez-Garrido et al., 2004; Ranguin et al., 2017; Chevallier et al., 2018, 2019; Guo and Chen, 2018; Pizarro et al., 2019). Under biotic conditions, involvement of corrinoids as cofactors in reductive dehalogenases found in organohalide respiring bacteria that transform a variety of organochlorides pollutants was also known (Schubert et al., 2018). Moreover, a dechlorination process was observed in non-organohalide-respiring bacteria and under these conditions, the implication of protein-free corrinoids was already suggested (Jagnow et al., 1977; Badea et al., 2009; Lomheim et al., 2020). This last point was confirmed in that study.

From an environmental point of view, it is highly plausible that corrinoids produced by bacteria could have a significant impact on the natural biodegradation of organochlorine compounds under anaerobic conditions. Pools of cobalamin are produced de novo and subject to complex trade-offs for salvage and remodeling in terrestrial and marine ecosystems (Heal et al., 2017; Lu et al., 2020). In contaminated sites, biostimulation of bacteria producing corrinoids could be a method of depollution (Guo and Chen, 2018). Although, the harsh reductive conditions, which are required for corrinoidmediated chlordecone and lindane biotransformations in the laboratory may not easily be met in polluted agricultural soils, the presence of degradation products in natural environments (Chevallier et al., 2019) leaves this possibility open.

On a smaller and easier to control scale, for example in reactors, biodegradation could be performed using bacteria producing corrinoids at high yield. Though anaerobic bacteria, for example from the genus Desulfovibrio, are known as producers of corrinoids (Men et al., 2014, 2015), bacteria from the genus Citrobacter like for instance Citrobacter sp.86 could be of great interest in co-metabolic degradations. As we show here, this facultative anaerobic bacterium that displays a versatile anaerobic metabolism involving cobalamin (e.g., synthesis of building blocks, degradation of glycerol, propanediol, ethanolamine, and glutamate...) can be easily manipulated genetically. Tools of the synthetic biology toolbox (Dvořák et al., 2017) like knockin and knockout strategies could therefore be implemented in Citrobacter sp.86 to determine the optimal corrinoids, enhance their production and test for further improvements in lindane, chlordecone, or other organochlorine transformations in the perspective of possible bioremediation improvement.

\section{CONCLUSION}

In this study, we show clearly, through the examination of Citrobacter sp.86 knockout mutant strains defective in cobalamin biosynthesis, that corrinoids are involved in chlordecone and lindane biotransfomations. This provides new information on the mechanistic issues of chlordecone transformation. In addition, the present work highlights the importance of cobalt insertion into the tetrapyrrole ring for these transformations.

Biotransformations mediated by corrinoids produced by Citrobacter sp.86 are not substrate-specific processes as shown here using different organochlorines compounds such as chlordecone (bishomocubane structure) and lindane $(\gamma$-hexachlorocyclohexane). Further investigations could extend the present degradation spectrum to other organochlorines. Furthermore, it would also be interesting to know how this bacterium is able to reduce its corrinoids to $\mathrm{Co}(\mathrm{I})$, an oxidation state that might be required for the ring-opening dechlorination of chlordecone.

\section{DATA AVAILABILITY STATEMENT}

The original contributions presented in the study are included in the article/Supplementary Material, further inquiries can be directed to the corresponding authors. 


\section{AUTHOR CONTRIBUTIONS}

DP and NF conceived the study, designed the experiments, and supervised the microbiology and molecular biology part. $\mathrm{AB}$, OD-N, SC, VD, DM, EU, and NF performed the experiments. OD-N, DM, P-LS, and NF carried out the data analysis. OD-N, $\mathrm{CF}, \mathrm{DP}$, and NF wrote the paper. $\mathrm{AB}, \mathrm{OD}-\mathrm{N}$, and $\mathrm{SC}$ assisted in the formatting of the Figures. SC, P-LS, JW, and DP helped to revise the manuscript. P-LS supervised and developed the analytical and monitoring methods. All authors participated in the discussion of the manuscript, and agreed on the final content.

\section{FUNDING}

Support was provided by Commissariat à l'Energie Atomique et aux Energies Alternatives (CEA), the center National de la Recherche Scientifique (CNRS), and the University Evry Val d'Essonne (UEVE). OD-N work was supported by the "IDI 2017" project funded by the IDEX Paris-Saclay, ANR-11-IDEX-0003-02.

\section{REFERENCES}

Álvarez, A., Yañez, M. L., Benimeli, C. S., and Amoroso, M. J. (2012). Maize plants (Zea mays) root exudates enhance lindane removal by native Streptomyces strains. Int. Biodeterior. Biodegradation 66, 14-18. doi: 10.1016/j.ibiod.2011.10.001

Badea, S. -L., Vogt, C., Weber, S., Danet, A. -F., and Richnow, H. -H. (2009). Stable isotope fractionation of $\gamma$-hexachlorocyclohexane (Lindane) during reductive dechlorination by two strains of sulfate-reducing bacteria. Environ. Sci. Technol. 43, 3155-3161. doi: 10.1021/es801284m

Bashir, S., Kuntze, K., Vogt, C., and Nijenhuis, I. (2018). Anaerobic biotransformation of hexachlorocyclohexane isomers by Dehalococcoides species and an enrichment culture. Biodegradation 29, 409-418. doi: 10.1007/ s10532-018-9838-9

Belghit, H., Colas, C., Bristeau, S., Mouvet, C., and Maunit, B. (2015). Liquid chromatography-high-resolution mass spectrometry for identifying aqueous chlordecone hydrate dechlorinated transformation products formed by reaction with zero-valent iron. Int. J. Environ. Anal. Chem. 95, 93-105. doi: 10.1080/03067319.2014.994615

Böltner, D., Morillas, S. M., and Ramos, J. -L. (2005). 16S rDNA phylogeny and distribution of Lin genes in novel hexachlorocyclohexane-degrading Sphingomonas strains. Environ. Microbiol. 7, 1329-1338. doi: 10.1111/j.14625822.2005.00820.x

Boyle, A. W., Phelps, C. D., and Young, L. Y. (1999). Isolation from estuarine sediments of a desulfovibrio strain which can grow on lactate coupled to the reductive dehalogenation of 2,4,6-Tribromophenol. Appl. Environ. Microbiol. 65, 1133-1340. doi: 10.1128/AEM.65.3.1133-1140.1999

Cabidoche, Y. -M., Achard, R., Cattan, P., Clermont-Dauphin, C., Massat, F., and Sansoulet, J. (2009). Long-term pollution by Chlordecone of tropical volcanic soils in the French West Indies: a simple leaching model accounts for current residue. Environ. Pollut. 157, 1697-1705. doi: 10.1016/j. envpol.2008.12.015

Camacho-Pérez, B., Ríos-Leal, E., Rinderknecht-Seijas, N., and Poggi-Varaldo, H. M. (2012). Enzymes involved in the biodegradation of hexachlorocyclohexane: a mini review. J. Environ. Manag. 95, 306-318. doi: 10.1016/j.jenvman.2011.06.047

Chaussonnerie, S., Saaidi, P. -L., Ugarte, E., Barbance, A., Fossey, A., Barbe, V., et al. (2016). Microbial degradation of a recalcitrant pesticide: chlordecone. Front. Microbiol. 7:2025. doi: 10.3389/fmicb.2016.02025

Chevallier, M. L., Cooper, M., Kümmel, S., Barbance, A., Le Paslier, D., Richnow, H. H., et al. (2018). Distinct carbon isotope fractionation signatures during biotic and abiotic reductive transformation of chlordecone. Environ. Sci. Technol. 52, 3615-3624. doi: 10.1021/acs.est.7b05394

\section{ACKNOWLEDGMENTS}

The authors would like to thank Denis Thibaut and Torsten Schubert for helpful discussions. They thank Susan Cure and Madeleine Bouzon for improving the manuscript. They also thank Benoit Doublet for providing plasmid pKD46Gm. The LABGeM (CEA/Genoscope \& CNRS UMR8030), the France Génomique and French Bioinformatics Institute national infrastructures (funded as part of Investissement d'Avenir program managed by Agence Nationale pour la Recherche, contracts ANR-10-INBS-09 and ANR-11INBS-0013) are acknowledged for support within the MicroScope annotation platform.

\section{SUPPLEMENTARY MATERIAL}

The Supplementary Material for this article can be found online at: https://www.frontiersin.org/articles/10.3389/fmicb.2020.590061/ full\#supplementary-material

Chevallier, M. L., Della-Negra, O., Chaussonnerie, S., Barbance, A., Muselet, D., Lagarde, F., et al. (2019). Natural chlordecone degradation revealed by numerous transformation products characterized in key French West Indies environmental compartments. Environ. Sci. Technol. 53, 6133-6143. doi: 10.1021/acs.est.8b06305

Cuozzo, S. A., Sineli, P. E., Davila Costa, J., and Tortella, G. (2017). Streptomyces sp. is a powerful biotechnological tool for the biodegradation of $\mathrm{HCH}$ isomers: biochemical and molecular basis. Crit. Rev. Biotechnol. 38, 719-728. doi: 10.1080/07388551.2017.1398133

Datsenko, K. A., and Wanner, B. L. (2000). One-step inactivation of chromosomal genes in Escherichia coli K-12 using PCR products. Proc. Natl. Acad. Sci. 97, 6640-6645. doi: 10.1073/pnas.120163297

Dawson, G. W., Weimer, W. C., and Shupe, S. J. (1979). Kepone - A case study of a persistent material. The American Institute of Chemical Engineers (AIChE) Symposium Series. 75, 366-374.

Della-Negra, O., Chaussonnerie, S., Fonknechten, N., Barbance, A., Muselet, D., Martin, D. E., et al. (2020). Transformation of the recalcitrant pesticide chlordecone by Desulfovibrio $\mathrm{sp} .86$ with a switch from ring-opening dechlorination to reductive sulfidation activity. Sci. Rep. 10:13545. doi: 10.1038/ s41598-020-70124-9

Dereumeaux, C., Saoudi, A., Guldner, L., Pecheux, M., Chesneau, J., Thomé, J. -P., et al. (2019). Chlordecone and organochlorine compound levels in the French West Indies population in 2013-2014. Environ. Sci. Pollut. Res. Int. doi: 10.1007/s11356-019-07181-9 [Epub ahead of print].

Dereven'kov, I. A., Salnikov, D. S., Silaghi-Dumitrescu, R., Makarov, S. V., and Koifman, O. I. (2016). Redox chemistry of cobalamin and its derivatives. Coord. Chem. Rev. 309, 68-83. doi: 10.1016/j.ccr.2015.11.001

Dogra, C., Raina, V., Pal, R., Suar, M., Lal, S., Gartemann, K. -H., et al. (2004). Organization of lin genes and IS6100 among different strains of hexachlorocyclohexane-degrading Sphingomonas Paucimobilis: evidence for horizontal gene transfer. J. Bacteriol. 186, 2225-2235. doi: 10.1128/ JB.186.8.2225-2235.2004

Doublet, B., Douard, G., Targant, H., Meunier, D., Madec, J. -Y., and Cloeckaert, A. (2008). Antibiotic marker modifications of $\lambda$ red and FLP helper plasmids, PKD46 and PCP20, for inactivation of chromosomal genes using PCR products in multidrug-resistant strains. J. Microbiol. Methods 75, 359-361. doi: 10.1016/j.mimet.2008.06.010

Dvořák, P., Nikel, P. I., Damborský, J., and de Lorenzo, V. (2017). Bioremediation 3.0: engineering pollutant-removing bacteria in the times of systemic biology. Biotechnol. Adv. 35, 845-866. doi: 10.1016/j.biotechadv.2017.08.001

Elango, V., Kurtz, H. D., Anderson, C., and Freedman, D. L. (2011). Use of $\gamma$-hexachlorocyclohexane as a terminal electron acceptor by an anaerobic 
enrichment culture. J. Hazard. Mater. 197, 204-210. doi: 10.1016/j. jhazmat.2011.09.080

Endo, R., Kamakura, M., Miyauchi, K., Fukuda, M., Ohtsubo, Y., Tsuda, M., et al. (2005). Identification and characterization of genes involved in the downstream degradation pathway of $\gamma$-hexachlorocyclohexane in Sphingomonas paucimobilis UT26. J. Bacteriol. 187, 847-853. doi: 10.1128/JB.187.3.847853.2005

Epstein, S. S. (1978). Kepone-Hazard Evaluation. Sci. Total Environ. 9, 1-62. doi: 10.1016/0048-9697(78)90002-5

Fernández-Bayo, F. D., Saison, C., Voltz, M., Disko, U., Hofmann, D., and Berns, A. E. (2013). Chlordecone fate and mineralisation in a tropical soil (andosol) microcosm under aerobic conditions. Sci. Total Environ. 463-434, 395-203. doi: 10.1016/j.scitotenv.2013.06.044

Fincker, M., and Spormann, A. M. (2017). Biochemistry of catabolic reductive dehalogenation. Annu. Rev. Biochem. 86, 357-386. doi: 10.1146/annurevbiochem-061516-044829

Fonseca, M. V., and Escalante-Semerena, J. C. (2000). Reduction of cob(III) alamin to cob(II)alamin in Salmonella enterica Serovar Typhimurium LT2. J. Bacteriol. 182, 4304-4309. doi: 10.1128/JB.182.15.4304-4309.2000

George, S. E., and Claxton, L. -D. (1988). Biotransformation of chlordecone by Pseudomonas species. Xenobiotica 18, 407-416. doi: 10.3109/00498258809041677

Guo, M., and Chen, Y. (2018). Coenzyme cobalamin: biosynthesis, overproduction and its application in dehalogenation-a review. Rev. Environ. Sci. Biotechnol. 17, 259-284. doi: 10.1007/s11157-018-9461-6

Heal, K. R., Qin, W., Ribalet, F., Bertagnolli, A. D., Coyote-Maestas, W., Hmelo, L. R., et al. (2017). Two distinct pools of B12 analogs reveal community interdependencies in the ocean. Proc. Natl. Acad. Sci. U. S. A. 114, 364-369. doi: 10.1073/pnas.1608462114

Heckel, B., McNeill, K., and Elsner, M. (2018). Chlorinated ethene reactivity with vitamin $\mathrm{B} 12$ is governed by cobalamin chloroethylcarbanions as crossroads of competing pathways. ACS Catal. 8, 3045-3066. doi: 10.1021/ acscatal.7b02945

Hiskia, A., Mylonas, A., Tsipi, D., and Papaconstantinou, E. (1997). Photocatalytic degradation of Lindane in aqueous solution. Pestic. Sci. 50, 171-174. doi: 10.1002/(SICI)1096-9063(199706)50:2<171::AID-PS565>3.0.CO;2-H

Huggett, R. J., and Bender, M. E. (1980). Kepone in the James River. Environ. Sci. Technol. 14, 918-923. doi: 10.1021/es60168a001

Jablonski, P. E., Pheasant, D. H., and Ferry, J. G. (1996). Conversion of Kepone by Methanosarcina Thermophila. FEMS Microbiol. Lett. 139, 169-173. doi: 10.1111/j.1574-6968.1996.tb08198.x

Jagnow, G., Haider, K., and Ellwardt, P. C. (1977). Anaerobic dechlorination and degradation of hexachlorocyclohexane isomers by anaerobic and facultative anaerobic bacteria. Arch. Microbiol. 115, 285-292. doi: 10.1007/BF00446454

Jennings, A. A., and Li, Z. (2015). Residential surface soil guidance applied worldwide to the pesticides added to the Stockholm convention in 2009 and 2011. J. Environ. Manag. 160, 226-240. doi: 10.1016/j.jenvman.2015.06.020

Jeter, R. M., Olivera, B. M., and Roth, J. R. (1984). Salmonella Typhimurium synthesizes cobalamin (vitamin B12) de novo under anaerobic growth conditions. J. Bacteriol. 159, 206-213. doi: 10.1128/JB.159.1.206-213.1984

Kumari, R., Subudhi, S., Suar, M., Dhingra, G., Raina, V., Dogra, C., et al. (2002). Cloning and characterization of Lin genes responsible for the degradation of hexachlorocyclohexane isomers by Sphingomonas Paucimobilis strain B90. Appl. Environ. Microbiol. 68, 6021-6028. doi: 10.1128/AEM.68.12. 6021-6028.2002

Lal, R., Dogra, C., Malhotra, S., Sharma, P., and Pal, R. (2006). Diversity, distribution and divergence of Lin genes in hexachlorocyclohexane-degrading Sphingomonads. Trends Biotechnol. 24, 121-130. doi: 10.1016/j.tibtech.2006.01.005

Lal, R., Pandey, G., Sharma, P., Kumari, K., Malhotra, S., Pandey, R., et al. (2010). Biochemistry of microbial degradation of hexachlorocyclohexane and prospects for bioremediation. Microbiol. Mol. Biol. Rev. 74, 58-80. doi: 10.1128/MMBR.00029-09

Laquitaine, L., Durimel, A., de Alencastro, L. F., Jean-Marius, C., Gros, O., and Gaspard, S. (2016). Biodegradability of $\mathrm{HCH}$ in agricultural soils from Guadeloupe (French West Indies): identification of the Lin genes involved in the $\mathrm{HCH}$ degradation pathway. Environ. Sci. Pollut. Res. 23, 120-127. doi: $10.1007 /$ s11356-015-5875-7

Le Déaut, J-Y, and Procaccia, C. (2009). Impacts de l'utilisation de la chlordécone et des pesticides aux Antilles: bilan et perspectives dévolution. Office parlementaire dévaluation des choix scientifiques et technologiques Rapport $\mathrm{n}^{\circ} 487$ (2008-2009). Availavle at: https://www.senat.fr/rap/r08-487/r08-487. html

Lesueur-Jannoyer, M., Cattan, P., Woignier, T., and Clostre, F. (2016). Crisis management of chronic pollution: Contaminated soil and human health. Boca Raton, US: CRC Press.

Lomheim, L., Laquitaine, L., Rambinaising, S., Flick, R., Starostine, A., Jean-Marius, C., et al. (2020). Evidence for extensive anaerobic dechlorination and transformation of the pesticide chlordecone $(\mathrm{C} 10 \mathrm{Cl} 10 \mathrm{O})$ by indigenous microbes in microcosms from Guadeloupe soil. PLoS One 15:e0231219. doi: 10.1371/journal.pone.0231219

Lu, X., Heal, K. R., Ingalls, A. E., Doxey, A. C., and Neufeld, J. D. (2020). Metagenomic and chemical characterization of soil Cobalamin production. ISME J. 14, 53-66. doi: 10.1038/s41396-019-0502-0

Macrae, I. C., Raghu, K., and Bautista, E. M. (1969). Anaerobic degradation of the insecticide lindane by Clostridium Sp. Nature 221, 859-860. doi: $10.1038 / 221859 \mathrm{a} 0$

Marks, T. S., Allpress, J. D., and Maule, A. (1989). Dehalogenation of lindane by a variety of porphyrins and corrins. Appl. Environ. Microbiol. 55, 1258-1261. doi: 10.1128/AEM.55.5.1258-1261.1989

Maudouit, M., and Rochoy, M. (2019). Systematic review of the impact of chlordecone on human health in the French West Indies. Therapie 74, 611-625. doi: 10.1016/j.therap.2019.01.010

Mehboob, F., Langenhoff, A. A. M., Schraa, G., and Stams, A. J. M. (2013). "Anaerobic degradation of lindane and other $\mathrm{HCH}$ isomers" in Management of microbial resources in the environment. eds. A. Malik, E. Grohmann and M. Alves (Dordrecht: Springer), 495-521.

Men, Y., Seth, E. C., Yi, S., Allen, R. H., Taga, M. E., and Alvarez-Cohen, L. (2014). Sustainable growth of Dehalococcoides mccartyi 195 by corrinoid salvaging and remodeling in defined lactate-fermenting consortia. Appl. Environ. Microbiol. 80, 2133-2141. doi: 10.1128/AEM.03477-13

Men, Y., Seth, E. C., Yi, S., Crofts, T. S., Allen, R. H., Taga, M. E., et al. (2015). Identification of specific corrinoids reveals corrinoid modification in dechlorinating microbial communities. Environ. Microbiol. 17, 4873-4884. doi: $10.1111 / 1462-2920.12500$

Middeldorp, P. J. M., Jaspers, M., Zehnder, A. J. B., and Schraa, G. (1996). Biotransformation of $\alpha-, \beta-, \quad \gamma-$, and $\delta$-hexachlorocyclohexane under methanogenic conditions. Environ. Sci. Technol. 30, 2345-2349. doi: 10.1021/ es $950782+$

Multigner, L., Rouget, F., Costet, N., Monfort, C., Blanchet, P., Kadhel, P., et al. (2018). Chlordécone: un perturbateur endocrinien emblématique affectant les Antilles Françaises. Bull Epidemiol. Hebd. 22-23, 480-485. http://invs. santepubliquefrance.fr/beh/2018/22-23/2018_22-23_4.html (Accessed October 27, 2020).

Nagata, Y., Endo, R., Ito, M., Ohtsubo, Y., and Tsuda, M. (2007). Aerobic degradation of lindane ( $\gamma$-hexachlorocyclohexane) in bacteria and its biochemical and molecular basis. Appl. Microbiol. Biotechnol. 76, 741-752. doi: $10.1007 / \mathrm{s} 00253-007-1066-\mathrm{x}$

Nichols, M. M. (1990). Sedimentologic fate and cycling of kepone in an estuarine system: example from the James River estuary. Sci. Total Environ. 97-98, 407-440. doi: 10.1016/0048-9697(90)90254-R

Nichols, M. M., and Cutshall, N. H. (1981). Tracing kepone contamination in James estuary sediments. Re'un. Cons. Int. Explor. Mer. 137.

Nolan, K., Kamrath, J., and Levitt, J. (2012). Lindane toxicity: a comprehensive review of the medical literature. Pediatr. Dermatol. 29, 141-146. doi: 10.1111/j. 1525-1470.2011.01519.x

Ohisa, N., and Yamaguchi, M. (1978). Degradation of gamma-BHC in flooded soils enriched with peptone. Agric. Biol. Chem. 42, 1983-1987. doi: 10.1080/00021369.1978.10863297

Orndorff, S. A., and Colwell, R. R. (1980). Microbial transformation of kepone. Appl. Environ. Microbiol. 39, 398-406. doi: 10.1128/AEM.39.2.398-406.1980

Pizarro, S., Gallardo, M., Gajardo, F., and Delgadillo, A. (2019). Electrochemical reduction of lindane using a cobaloxime containing electron-withdrawing groups. Inorg. Chem. Commun. 99, 164-166. doi: 10.1016/j.inoche.2018. 10.014

Qiao, W., Jácome, L. A. P., Tang, X., Lomheim, L., Yang, M. I., Gaspard, S., et al. (2020). Microbial communities associated with sustained anaerobic reductive dechlorination of $\alpha-, \beta-, \gamma$-, and $\delta$-hexachlorocyclohexane isomers to monochlorobenzene and benzene. Environ. Sci. Technol. 54, 255-265. doi: 10.1021 /acs.est.9b05558 
Quintero, J. C., Moreira, M. T., Feijoo, G., and Lema, J. M. (2005). Anaerobic degradation of hexachlorocyclohexane isomers in liquid and soil slurry systems. Chemosphere 61, 528-536. doi: 10.1016/j.chemosphere.2005.02.010

Ranguin, R., Durimel, A., Karioua, R., and Gaspard, S. (2017). Study of chlordecone desorption from activated carbons and subsequent dechlorination by reduced cobalamin. Environ. Sci. Pollut. Res. 24, 25488-25499. doi: 10.1007/ s11356-017-9542-z

Robles-González, I. V., Fava, F., and Poggi-Varaldo, H. M. (2008). A review on slurry bioreactors for bioremediation of soils and sediments. Microb. Cell Factories 7, 1-16. doi: 10.1186/1475-2859-7-5

Rodríguez-Garrido, B., Camps Arbestain, M., and Macías, F. (2004). Reductive dechlorination of $\alpha$-, $\beta-, \delta$-, and $\gamma$-hexachlorocyclohexane isomers by hydroxocobalamin in the presence of either dithiothreitol or titanium(III) citrate as reducing agents. Environ. Sci. Technol. 38, 5046-5052. doi: 10.1021/ es030153x

Roth, J. R., Lawrence, J. G., and Bobik, T. A. (1996). Cobalamin (coenzyme B12): synthesis and biological significance. Annu. Rev. Microbiol. 50, 137-181. doi: 10.1146/annurev.micro.50.1.137

Saez, J. M., Alvarez, A., Fuentes, M. S., Amoroso, M. J., and Benimeli, C. S. (2017). "An overview on microbial degradation of Lindane" in microbeinduced degradation of pesticides. ed. S. N. Singh. (Springer, Cham).

Sakakibara, F., Takagi, K., Kataoka, R., Kiyota, H., Sato, Y., and Okada, S. (2011). Isolation and identification of dieldrin-degrading Pseudonocardia sp. strain KSF27 using a soil-charcoal perfusion method with aldrin trans-diol as a structural analog of dieldrin. Biochem. Biophys. Res. Commun. 411, 76-81. doi: 10.1016/j.bbrc.2011.06.096

Saley, F. Y., Dickson, L., and Rodgers, J. H. Jr. (1982). Fate of lindane in the aquatic environment: rate constants of physical and chemical processes. Environ. Toxicol. Chem. 1, 289-297. doi: 10.1002/etc.5620010404

Schrauzer, G. N., and Katz, R. N. (1978). Reductive dechlorination and degradation of mirex and kepone with vitamin B12s. Bioinorg. Chem. 9, 123-142. doi: 10.1016/S0006-3061(00)80285-9

Schubert, T., Adrian, L., Sawers, R. G., and Diekert, G. (2018). Organohalide respiratory chains: composition, topology and key enzymes. FEMS Microbiol. Ecol. 1:94. doi: 10.1093/femsec/fiy035

Senoo, K., and Wada, H. (1989). Isolation and identification of an aerobic $\gamma$-HCH-decomposing bacterium from soil. J. Soil Sci. Plant Nutr. 35, 79-87. doi: 10.1080/00380768.1989.10434739

Shelton, A. N., Seth, E. C., Mok, K. C., Han, A. W., Jackson, S. N., Haft, D. R., et al. (2019). Uneven distribution of cobamide biosynthesis and dependence in bacteria predicted by comparative genomics. ISME J. 13, 789-804. doi: 10.1038/s41396-018-0304-9

Terán, J. E., Zambrano, C. H., Mora, J. R., Rincón, L., and Torres, F. J. (2018). Theoretical investigation of the mechanism for the reductive dehalogenation of methyl halides mediated by the CoI-based compounds cobalamin and cobaloxime. J. Mol. Model. 24:316. doi: 10.1007/s00894-018-3844-Z
Trotman, R. C., and Nichols, M. M. (1978). Kepone in bed sediments of the James River Estuary. Special scientific report No. 91. Virginia Institute of Marine Science: College of William and Mary.

Unger, M., and Vadas, G. (2017). Kepone in the James River Estuary: past, current and future trends. Virginia Institute of Marine Science: William \& Mary.

van der Ploeg, J., van Hall, G., and Janssen, D. B. (1991). Characterization of the haloacid dehalogenase from xanthobacter autotrophicus GJ10 and sequencing of the DhlB gene. J. Bacteriol. 173, 7925-7933. doi: 10.1128/ jb.173.24.7925-7933.1991

Vijgen, J., de Borst, B., Weber, R., Stobiecki, T., and Forter, M. (2019). HCH and lindane contaminated sites: European and global need for a permanent solution for a long-time neglected issue. Environ. Pollut. 248, 696-705. doi: 10.1016/j.envpol.2019.02.029

Vilardebo, A., Beugnon, M., Melin, P., Lecoq, J., and Aubert, B. (1974). Chlordecone et autres insecticides dans la lutte contre le charançon du bananier Cosmopolites sordidus Germ. Fruits 29, 267-278.

Wacławek, S., Silvestri, D., Hrabák, P., Padil, V. V. T., Torres-Mendieta, R., Wacławek, M., et al. (2019). Chemical oxidation and reduction of hexachlorocyclohexanes: a review. Water Res. 162, 302-319. doi: 10.1016/j. watres.2019.06.072

Wilson, N. K., and Zehr, R. D. (1978). Structures of some Kepone photoproducts and related chlorinated pentacyclodecanes by carbon-13 and proton nuclear magnetic resonance. J. Organomet. Chem. 44, 1278-1282. doi: 10.1021/ jo01322a020

Zaleska, A., Hupka, J., Wiergowski, M., and Biziuk, M. (2000). Photocatalytic degradation of lindane, p,p'-DDT and methoxychlor in an aqueous environment. J. Photochem. Photobiol. 135, 213-220. doi: 10.1016/S1010-6030(00)00296-3

Zhang, N., Bashir, S., Qin, J., Schindelka, J., Fischer, A., Nijenhuis, I., et al. (2014). Compound specific stable isotope analysis (CSIA) to characterize transformation mechanisms of $\alpha$-hexachlorocyclohexane. J. Hazard. Mater. 280, 750-757. doi: 10.1016/j.jhazmat.2014.08.046

Zhang, W., Lin, Z., Pang, S., Bhatt, P., and Chen, S. (2020). Insights into the biodegradation of lindane ( $\gamma$-hexachlorocyclohexane) using a microbial system. Front. Microbiol. 11:522. doi: 10.3389/fmicb.2020.00522

Conflict of Interest: The authors declare that the research was conducted in the absence of any commercial or financial relationships that could be construed as a potential conflict of interest.

Copyright (C) 2020 Barbance, Della-Negra, Chaussonnerie, Delmas, Muselet, Ugarte, Saaidi, Weissenbach, Fischer, Le Paslier and Fonknechten. This is an open-access article distributed under the terms of the Creative Commons Attribution License (CC BY). The use, distribution or reproduction in other forums is permitted, provided the original author(s) and the copyright owner(s) are credited and that the original publication in this journal is cited, in accordance with accepted academic practice. No use, distribution or reproduction is permitted which does not comply with these terms. 